\title{
Por um modelo unificado da cognição discursiva*
}

\section{Paulo Eduardo Lopes}

\section{1- Introdução}

Algumas tentativas têm sido feitas, recentemente, de sistematizar as aquisições teóricas dispersas nos trabalhos dos semioticistas greimasianos acerca dos elementos enunciativos do discurso, no rumo de um modelo unitário e coerente como o que já se logrou elaborar para a descrição do enunciado. Há, inclusive, propostas que querem ver as estruturas da enunciação tratada de modo análogo às do enunciado: Barros $^{(1)}$, por exemplo, retomando idéias lançadas por Hammad (2), esboça uma análise das estruturas narrativas da enunciação, atribuindo diferentes papéis actanciais às suas instâncias, segundo, ao nivel das suas estruturas discursivas, a enunciação seja tomada como a realização do tema da produção ou do tema da comunicação do enunciadodiscurso.

Sem pretender estender-nos, aqui, sobre as possibilidades e os problemas abertos por tais propostas, reteremos alguns de seus pontos para enfocar as funçōes enunciativas desempenhadas, nós limites do enunciado, pelas instâncias da dimensão cognitiva.

(*) - Resumo parciai do Capítuio IV da dissertação de mestrado A condição humana. Estudos de semiótlea da enunciaçãoem Magritte, defendida em setembro de 1989, na Escola de Comunicaçōes e Artes (ECAUSP). 


\section{2- A dimensão cognitiva na teoria-padrão greimasiana}

A estrutura cognitiva elementar tem sido descrita como a relação entre um sujeito e um objeto de conhecimento, estabelecida pelo enunciado:

\section{$s \cap 0$}

Greimas e Courtès (3) reconhecem, ainda, que a dimensāo cognitiva do discurso, constituída pela integração desses enunciados elementares, pressupōe necessariamente a existência de uma dimensão pragmática, que lhe serve de referente interno e à qual é hierarquicamente superior. Com isso, consolidouse na teoria padrão o seguinte esquema do enunciado cognitivo mínimo:

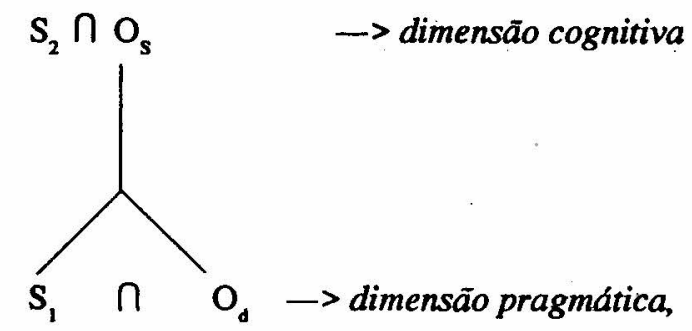

onde:

$S_{1}=$ sujeito de estado / de fazer pragmático;

$O_{d}=$ objeto-valor descritivo;

$S_{2}=$ sujeito cognitivo;

$\mathrm{O}_{\mathrm{s}}=$ objeto-valor de conhecimento.

A partir dessa concep̧ão, as pesquisas levaram a distinguir-se diversos tipos de sujeitos cognitivos, de acordo com os papéis temáticos manifestados no discurso: informante, narrador, narratário, observador, etc. Os vários sujeitos 
cognitivos seriam encarregados da construção do saber discursivo, desempenhando, no que tange à dimensão cognitiva, as funções atribuíveis, em última instância, a enunciador e enunciatário -- respectivamente, destinador e destinatário implícitos da enunciação:

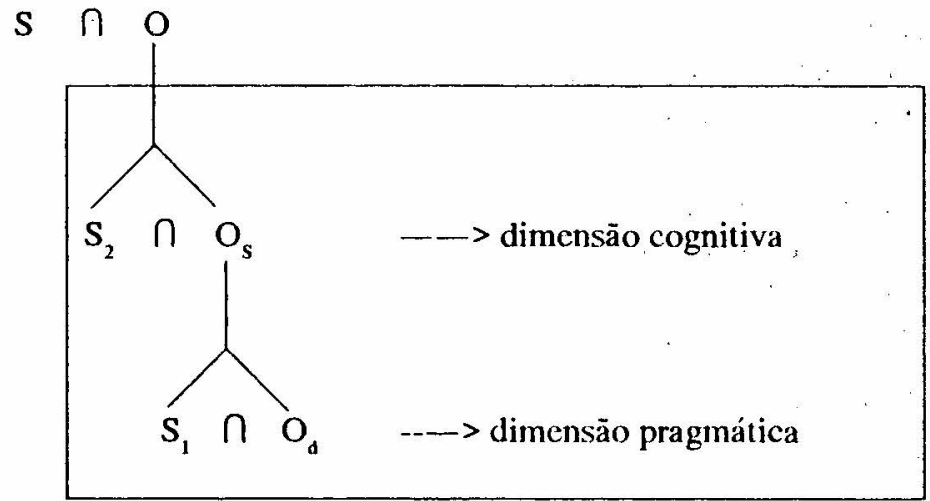

onde:

$S=$ sujeito da enunciação (enunciador/enunciatário)

$\mathrm{O}=$ enunciado-discurso

\section{3- Avaliação}

A nosso ver, o principal problema suscitado pela multiplicação dos sujeitos cognitivos a que levaram as pesquisas está em que tal fato - que corresponde a um refinamento dos instrumentos descritivos da cognição discursiva - não se fez acompanhar, até agora, de um esforço de sistematização que fosse capaz de articular os diferentes papéis temáticos entre si. Em outros tcrmos, pode-se fazer o inventário das várias instâncias cognitivas presentes $\mathrm{cm}$ dado discurso, mas fica-se sem saber exatamente como esse amontoado de intermediários pode construir outra coisa que não um amontoado de conhecimentos díspares. Ademais, todo trabalho descritivo assim formulado corre o risco de contaminar-se com as peculiaridades do discurso tomado por objeto, generalizando o que não é senão particular (e vice-versa) (4). Buscando contornar esses problemas, faremos uma rápida reflexão sobre a natureza temática da dimensão cognitiva. 


\section{4- Os niveis cognitivos}

Como já deixamos registrado, Barros sugere que a enunciação pode ser contemplada como uma configuração que subsume dois percursos temáticos complementares: o de produção e o de comunicação do enunciado-discurso. Se considerarmos, em seguida, que a dimensão cognitiva é uma das componentes da esfera enunciativa (assim como haveria uma dimensão pragmática e uma dimensão patemica da enunciação), parece lícito afïmar, analogamente, que todo ato cognitivo pode ser descrito como a produção e a comunicação de um saber. Assim, as diversas instâncias cognitivas seriam classificáveis segundo a natureza tcmática do saber: o sujeito observador, por exemplo, cncarregar-seia de produzir conhecimentos: o sujeito informante, bem como o sujeito narrador, estaria incubido de comunicar conhecimentos. extraidas:

Alguma consequências dessa classificaçāo podem ser imediatamente

a) a dimensão cognitiva de tolo discurso deverá ser descrita em dois niveis complementares e necessários: o da produção c o da comunicação do saber;

b) quanto às instâncias cognitivas, haverá pelo menos um sujeito cncarregado da produção, um sujeito encarregado da transmissão e outro da recepção do saber, ainda que, a nível actorial, esses actantes scjam investidos num único ator, ou em vários atores, ou permaneçam implícitos na manifestação;

c) não poderíamos fixar, exceto por uma abstração metodológica, apenas a função de produzir o saber para determinado actante, ou apenas a função de comunicar o saber para outro actante; basta lembrar que todo observador, para executar seu papel, deve comunicar para si próprio aquilo que observa (5), do mesmo modo que todo narrador deve observar um objeto para saber o que vai comunicar: a produção e a comunicação de um conhecimento são funçōes interdependentes, atị̣adas simultaneamente em cada ato cognitivo. 


\section{5- Hierarquia dos niveis no modelo}

Cabe, em seguida, indagar sobre o modo de articulação dos dois níveis cognitivos entre si. Sempre ressalvando o caráter puramente metodológico da distinção realizada, admitiremos que, assim como todo saber, para produzir-se, requer a existência de uma dimensão pragmática como referente; todo saber, para ser comunicado requer que se postule ter sido previamente produzido. Portanto, diremos que o nível da comunicação pressupõe o nível da produção do saber, que lhe é hierarquicamente inferior.

\section{6- Esquema gráfico}

Incluiremos as reflexões que realizamos no modelo esquemátiço produzido acima. Para tanto, preservando uma terminologia que, em essência, é predominantemente visual - cfe. observador, ponto de vista, perspectiva, etc. lançaremos mão do conceito de espetáculo, já utilizado em semiótica, chamando os níveis do gráfico de cenas:

D) NÍVEL DA CENA DE ENUNCIAÇĀO NÃO ENUNCIADA (saber sobre a representação) $S \cap 0$

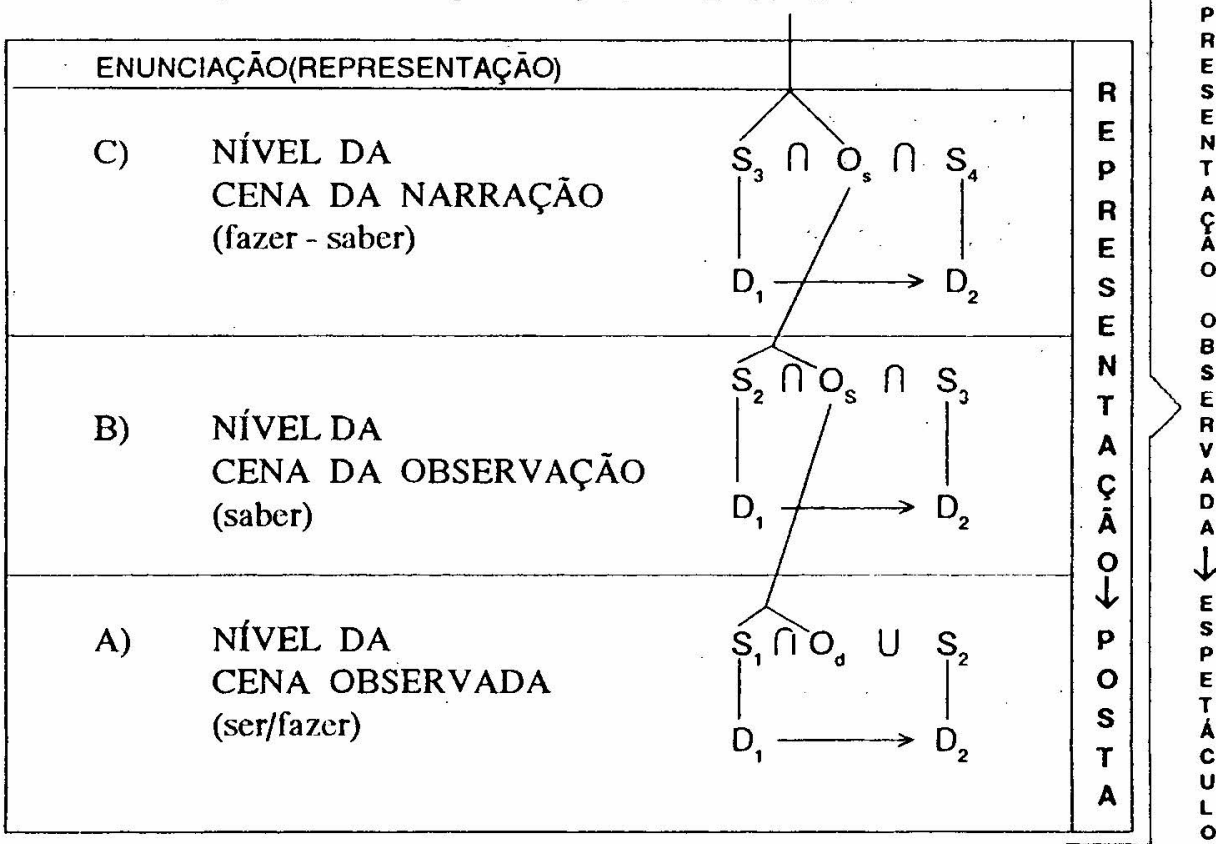




\section{Parâmetros de definição das funções cognitivas}

O modelo assim produzido visa a șistematizar as operações cognitivas que, articulando-se entre si, realizam o saber discursivo como uma totalidade de sentido, diferente da simples soma dos saberes parciais de que o enunciado se constrói. Trata-se, é evidente, de considerar que o trabalho enunciativo consiste, dentro desta perspectiva, na contextualização dos conhecimentos no intérior de esferas cognitivas cada vez mais amplas.

\section{1- Articulaçōes contextuais}

As funçòes exercidas pelas instâncias de cada nívcl podem scr comparadas com aquelas dos trés textos produzidos pelas propriedades necessárias do discurso registradas por Lopes, em artigo publicado em outro número desta revista (7):

- a fundação da realidade a ser conhecida: função atribuível aos níveis da Cena Observada (quanto aos contextos postos e da Cena da Enunciação Náo Enunciada (quanto aos contextos pressupostos do discurso);

- a predicação da realidade fundada: função desempenhada pelas instâncias do nivel da Cena da Observação, que produziriam saberes locais e parciais sobre detcrminados objetos;

- a interpretação dessa predicação: função das instâncias do nível da Cena da Narração, incumbidas de coerentizar e dotar de sentido narratológico os saberes parciais que tem por objeto.

\section{2- Aportes paradigmáticos e sintagmáticos}

Tais propriedades podem ser, ainda aproximadas da definição das articulações sêmicas que constróem o semema, na concepçāo de Assis Silva ${ }^{(8)}$ :

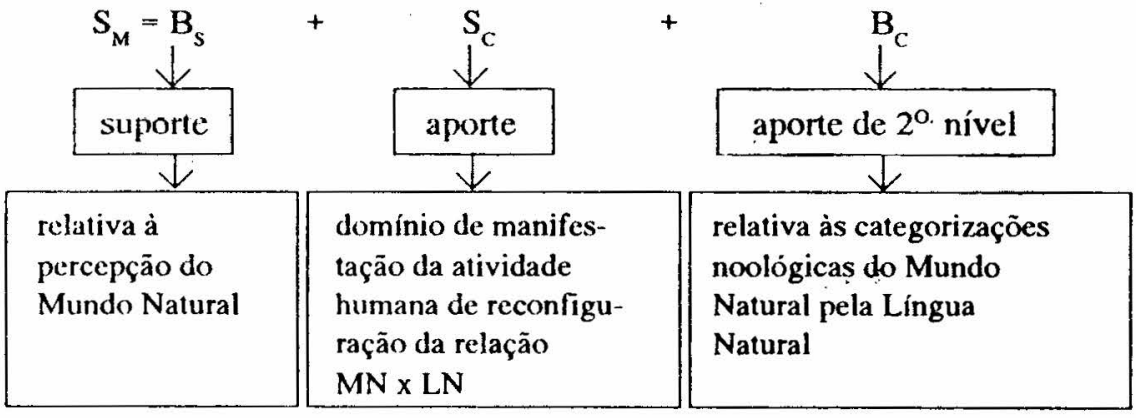


onde:

$S_{M}=$ semema;

$\mathrm{B}_{\mathrm{S}}=$ base sêmica, figura nuclear simples;

$\mathrm{S}_{\mathrm{C}}=$ semas contextuais;

$\mathrm{B}_{\mathrm{C}}=$ base classemática.

A comparação entre as caracteristicas dos $S_{C}$ e da $B_{C}$ torna tem claro que, enquanto os primciros sāo dependentes da figura nuclear simples, produzindothe um contexto minimo, de curto alcance, a segunda é criadora de contextos de amplo alcance, nos quais todos os contextos mínimos podem ser inclúidos, construindo um texto. Dito de outro modo, os semas contextuais incluem a base sêmica no âmbito de um paradigma figurativo, cujas virtualidades são, por seu turno, submetidas a uma seleção com base nas coerções do contexto sintagmático em que deve ser "costurado", produzindo uma isotopia de leitura. Analogamente, os níveis do modelo cognitivo realizam diferenciados aportes sobre os objetos de uma dimensạ̃o pragmática de suporte, de tal forma que podemos definir o seu funcionamento como segue:

- Cena da Observação: produção dosaber por contextualização paradig: mática do objeto;

- Cena da Narração: transmissão do saber por contextualizaçâo sintag: mática do objeto.

O saber em trânsito no modelo pode ser textualizado $\mathrm{cm}$ qualquer nivel de seu percurso. Assim, podemos prever dois efeitos de sentido, segundo o nivel cognitivo focalizado na textualização:

- textualização no nível da Cena da Observação = saber conotado (isto é, diversos saberes paradigmáticos simultaneamente sintagmatizados, apontando para diversas possibilidades conibinatórias e leituras pluriisotópicas);

- textualização no nivel da Cena da Narração = saber denotado (isto c, sintagmatização monoisotópica dos saberes produzidos, "costurados" narratologícamente por força de uma recategorização classemática) ${ }^{(9)}$. 


\section{8- O ponto de vista: focalização e perspectivização}

Cada instância da dimensão cognitiva, costuma-se dizer, impõe um ponto de vista sobre os objetos a serem conhecidos. Sabe-se que um ponto de vista define-se como sendo, ao mesmo tempo, "uma decupagem e uma valorização" ${ }_{(10)}$ do univerșo de referência, ou seja:

- uma focalização, processo que funda a realidade de que se vai falar $\mathrm{e}$ que funda, concomitantemente, aquele que vai falar dessa realidade, estabelecendo, portanto, a relaçāo espectador/cspetáculo; e

- uma perspectivização, processo de predicação/interpretação da realidade fundada.

Como vimos, os processos cognitivos podem ser descritos enquanto scleções e combinações de elementos paradigmáticos e sintagmáticos, os quais, a nível profundo, organizam-se a cada vez segundo uma estrutura elementar binária. Dissci podemos inferir que há sempre duas manciras de atualização de qualçuer relação entre termos, esomente duas: pela compreensāo das diferenças que os distinguem ou pela compreensão das identidades que mantém entre si. Se tomamos de empréstimo a Benveniste os conceitos de forma (a capacidade de uma unidade linguística de dissociar-se em constituintes de nível inferior) e de sentido (a capacidade de uma unidade linguistica de integrar uma unidade de nivel superior) (11), concluímos, enfim, que o saber construído sobre um objeto qualquer pode ser entendido por um de dois modos:

$$
\begin{aligned}
& \text { - saber = forma do objeto; } \\
& \text { - saber = semtido do objeto. }
\end{aligned}
$$

Entretanto, o conhecimento tem que ser atribuivel a um sujeito, em sua relação com um objeto. Na dependéncia do saber construído, poder-sc-á classilicar a relação cognitiva como:

- Perspectivizaçāo analítica: o sujcito compreende o objeto pela sua forma;

- Perspectivizaçāo sintética: o sujeito compreende o objeto pelo scu sentido. 


\title{
9- Verificação - relâmpago
}

Vejamos, por exemplo, o que ocorre com o seguinte poema de Décio Pignatari:

\author{
"FEMME \\ Elle s'ouvre \\ elle s'offre \\ elle souffre"
}

a) focalização: funda um objeto a ser conhecido ( "femme ") e um sujeito do conhecimento (que, no caso, permanece implícito);

b) perspectivização:

- no níve 1 da Cena da Observação: o sujeito cognitivo observador produz, por perspectivização analítica, dois contextos paradigmáticos de integração do objeto:

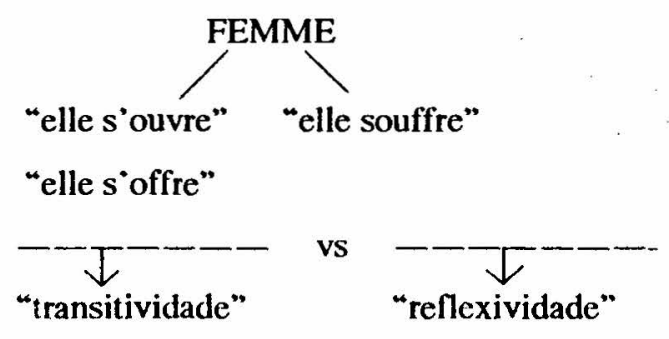

- no nível da Cena da Narração: o sujẹto cognitivo narrador integra os saberes antagônicos produzidos no nivel inferior, por um processo de perspectivização sintética:

"transitividade" vs "reflexividade"

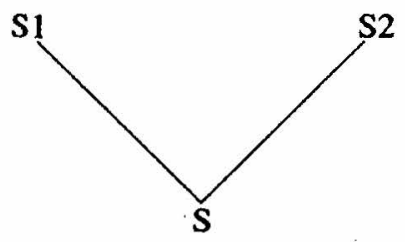

"relacionamento" 
Se analisamos o plano da expressão do poema, descrevemos um outro percurso cognitivo, em que há uma espécie de inversāo de perspectiva:

- no nivel da Cena da Observação, produz-se um saber sobre o sentido de dois termos-objeto, por perspectivizaçāo sintética:

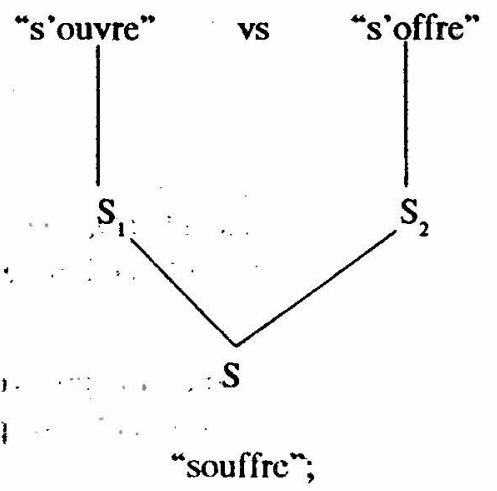

- no nível da Cena da Narraçāo, esse percurso é refeito, por análise, sendo compreendido como uma segunda isotopia de leitura do poema, que poderiamos traduzir aproximadamente como:

"sofrer é a conseqüência inevitável de abrir-se e oferecer-se ao outro", ou mesmo:

"sofrer está contido em abrir-se e oferever-se":

"souffre" $\simeq$ "s'ouvre" + "s'offre". 


\section{0- Resumo}

Propomos, para visualização do conjunto, o seguinte gráfico:

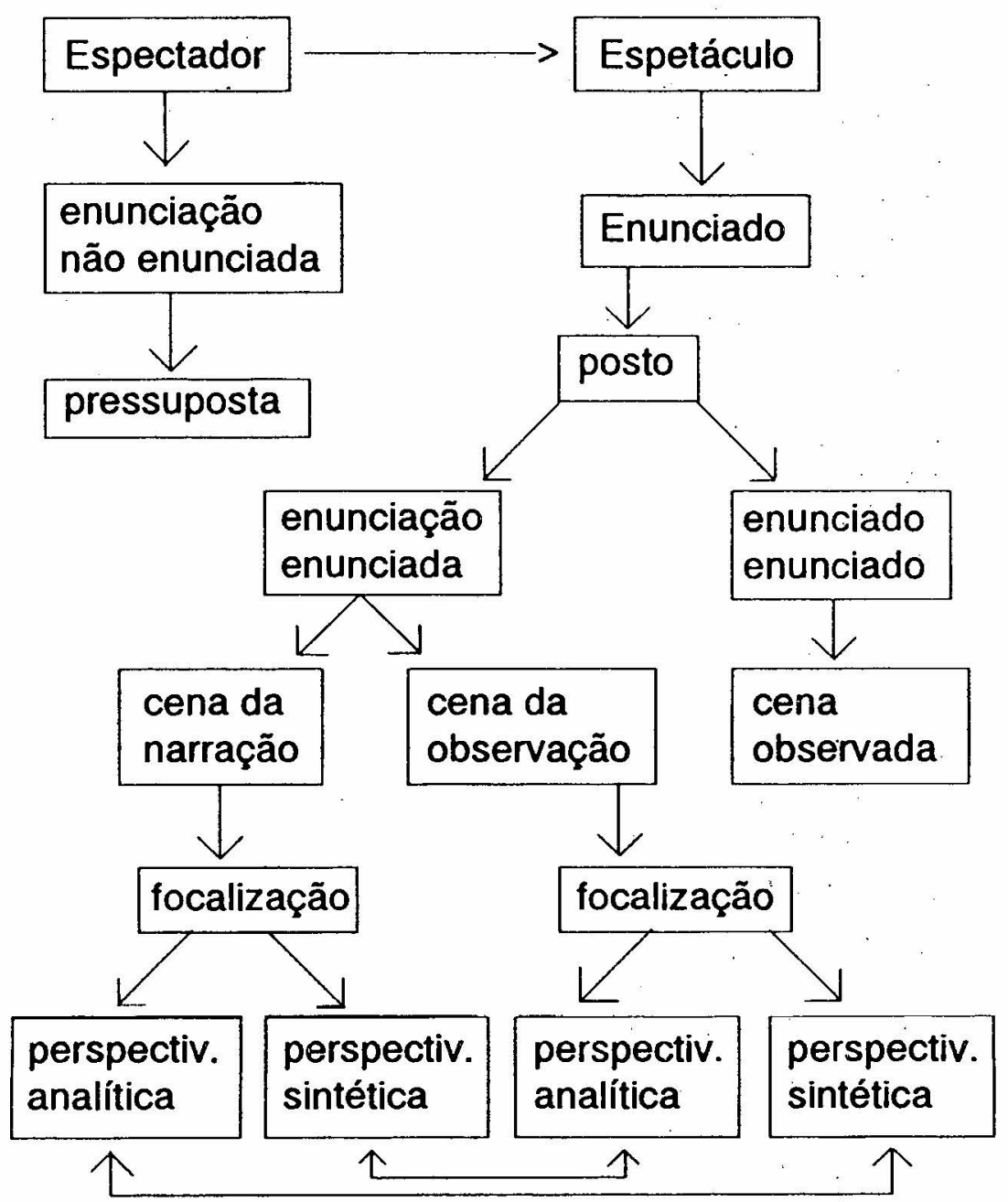




\section{1 - Ampliação do campo}

$O$ trabalho que expusemos em linhas gerais deveria enquadrar-se na esfera de pesquisas mais amplas sobre o saber e a dimensão cognitiva do discurso, tais como aquelas realizadas por Fontanille, em Le savoir partagé. Começando com a análise do "núcleo sêmico /saber/», ele desenvolve uma tipologia cognitiva onde distingue entre saberes "semióticos" e sabcres "metasemióticos" e, entre estes, saberes meta-semióticos "inferenciais" (“cujo conteúdo é o funcionamento do percurso gerativo da significação") e saberes metasemióticos "transversais" (que permitiriam a integração das diversas "ordens" de grandezas semióticas no interior de um mesmo nível do percurso gerativo) (12). Tendo em vista uma tal tipologia, nosso modelo cognitivo devcria dar conta tanto da articulação de saberes propriamente "semióticos" (ver nível da Cena da Observação) quanto de saberes meta-semióticos de tipo transversal (os quais, em última análise, cuidariam da integração dos saberes semióticos no âmbito de uma isotopia cognitiva produzida na Cena da Narraçāo). Restaria, finalmente, encontrar um lugar nesse modelo para a instalação dos saberes inferenciais, capazes de abri o caminho dos estudos sobre o problema da conversão entre os niveis do percurso gerativo.

\section{NOTAS}

1- Ver Teoria do discurso: fundamentos semióticos, de Diana Luz Pessoa de Barros (1988), págs. 136 a 140.

2- Manar Hammad. “L' Énonciation: Procès et Système”, in: PARRET, org. (1983), págs. 35 a 46.

3- GREIMAS \& COURTÈS (1983), pág. 52.

4- Temos um exemplo de particularização de um fenômeno universal da discursivização no seguinte trecho do Dicionário de semiótica, de Greimas e Courtès:

"Assịm entendida, a definição de espetáculo compreende, do ponto de vista interno, caracteristicas tais como presença de um espaço triclimensional fechado, distribuiçăo proxêmica, etc., ao passo que, do ponto de vista externo, ela implica a presença de um actante observador (com o que se excluem dessa definição as cerimônias, os rituais miticos, por exemplo, em que a presença de expectadores näo é necessária)" (GREIMAS \& COURTÈS, op. cit., pág. 452 - grifo nosso). 
O equívoco de considerar como facultativa a existência de certas instâncias cognitivas necessárias à mise en discours parece-nos uma decorrência do modo assistemático como a dimensão do saber tem sido descrita.

5- O papel do sujeito observador é complexo: quanto à performance, caracteriza-se por uma estrutura temática reflexiva (subsumindo destinador e destinatário na construção do saber); quanto à competência, possui uma estrutura temática transitiva (isto é, ele é o delegado -- logo, o destinatário do sujeito enunciador, que the confere o poder-observar em seu nome ou em nome de seu grupo social).

6- Ao tempo em que não parece haver problema em instalar, como instância cognitivas da Cena da Narração, a dupla narrador/ narratário, a natureza temática do saber produzido na Cena da Observação, com características simultaneamente reflexivas e transitivas (cfe. nota no. 5), dificulta a aplicaçăo do nome de observador à dupla de sujeitos aí posicionada: o sujeito $S_{3}$ seria apenas um "desmembramento" de $S_{2}$, ou antes, a explicitaçào da competência paradigmática do observador $S_{2}$. Talvez, a melhor altemativa seja conservar o nome de observador para $S_{2}$ e adotar o nome de "observatário" para $\mathrm{S}_{3}$, conforme sugestāo do prof. Eduardo Peñuela Cañizal.

7- Edward Lopes. “Articulaçōes Contextuais do Discurso”. Signilicaçāo. Araraquara, C.E.S., 1985, nº 5, págs. 15 a 33.

8- Ignácio Assis Silva. “A Configuração Semântica do Texto”. Revista de Cultura Vozes, Vol. LXIX, n 3, págs. 171 a 180; e " $A$ Construção do Ator: do Sígnico ao Simbólico". Significação. São Paulo, C.E.S., 1987, Nº 6, págs. 51 a 57.

9- Evidentemente, quando dizemos que a textualização do saber pode dar-se a partir da Cena da Observação, não se trata de escamotcar o trabalho cognitivo da Cena da Narraçāo; trata-se, ao contrário, da distinção entre dois diferentes programas narrativos a serem cumpridos pelos sujeitos cognitivos da própria Cena da Narraçāo:

-- PN, F (produzir saber conotado = textualização do saber ao nivel da Observação); 
- $\mathrm{PN}_{2}: \mathrm{F}$ (produzir saber denotado = textualizaçảo do saber ao nível da Narração).

Ressaltemos que, no caso de realizar-se o $\mathrm{PN}_{1}$, a função classemática aparece como criadora de uma isotopia global que poderíamos expressmar como "diversas isotopias de leitura sāo facultadas".

10- Greimas e Courtès (1986), pág. 171.

11- Émile Benveniste (1966), págs, 126 a 127.

12- Jacques Fontanille (1987), págs. 21 a 34 e 49 a 54.

\section{BIBLIOGRAFIA}

ASSIS SILVA, I. 1975. “A Configuração Semântica do Texto”. Revista de Cultura Vozes, vol. LXIX, n 3, págs. 171 a 180.

.1987. “A Construção do Ator: do Sígnico ao Simbólico". Significação. São Paulo, C.E.S., nº 6, págs: 51 a 57.

BARROS, D.L.P. de. 1988. Teoria do discurso: fundamentos semióticos. São Paulo, Atual.

BENVENISTE, E. 1966. Problèmes de linguistique générale. Paris, Gallimard.

FONTANILLE, J. 1987. Le savoir partagé. Sémiotique et théorie de la connaissance chez Marcel Proust. Paris-Amsterdam, HadèsBenjamins.

GREIMAS, A.J. \& COURTÈS, J. 1983. Dicionário de semiótica. Sāo Paulo, Cultrix.

1986. Sémiotique. Dictionnaire raisonné de la théorie du langage. II. Paris, Hachette.

HAMMAD, M. 1983. “L'Énonciation: Procés et Système”, in: PARRET (org.). La mise en discours. Revista Langages, Paris, Didier-Larousse, $n^{\circ} 70$, págs. 35 a 46.

LOPES, E. 1985. “Articulações Contextuais do Discurso”. Significação. Araraquara, C.E.S., $n^{\circ} 5$, págs. 15 a 33. 